\title{
The role of protected areas in supporting human health : a call to broaden the assessment of conservation outcomes
}

\section{Terraube, Julien}

2017-04

Terraube , J , Fernandez-Llamazares , A \& Cabeza , M 2017 , ' The role of protected areas in supporting human health : a call to broaden the assessment of conservation outcomes ' , Current Opinion in Environmental Sustainability , vol. 25 , pp. 50-58 . https://doi.org/10.1016/j.cosust.2017.08.005

http://hdl.handle.net/10138/311876

https://doi.org/10.1016/j.cosust.2017.08.005

cc_by_nc_nd

acceptedVersion

Downloaded from Helda, University of Helsinki institutional repository.

This is an electronic reprint of the original article.

This reprint may differ from the original in pagination and typographic detail.

Please cite the original version. 
1 The role of Protected Areas in supporting human health: a call to broaden the assessment of 2 conservation outcomes

3 Julien Terraube ${ }^{1 *}$, Álvaro Fernández-Llamazares ${ }^{1} \&$ Mar Cabeza $^{1}$

4

$5{ }^{1}$ Metapopulation Research Centre (MRC), Department of Biosciences, University of Helsinki, 6 Finland.

7

$8 \quad *$ Corresponding author: Julien Terraube

9 Address: Metapopulation Research Centre (MRC), Department of Biosciences, University of 10 Helsinki, Finland. Email: julien.terraube-monich@helsinki.fi. Tel: +358 468423149. 


\section{Abstract}

Ongoing global biodiversity loss has far-reaching consequences for human health and well-being. While Protected Areas (PAs) have become a major policy instrument for biodiversity conservation, their role in supporting human health remains unclear. Here, we synthesize both positive and negative aspects of PAs on different dimensions of human health and provide several theoretical advances to assess the effectiveness of PAs in promoting human health. We finally identify three major research gaps requiring urgent attention. Implementing an interdisciplinary research program remains a priority to better comprehend the linkages between human health, ecosystem services and conservation policies at global scale. We believe this is key to improve the management of PAs and their surrounding areas and foster co-benefits for biodiversity and human health.

\section{Keywords}

Conservation; Ebola; Food Security; Human health; Protected Area Effectiveness.

\section{Highlight}

- Global biodiversity loss impacts human health and well-being

- The overall health potential of PAs remains under-recognized

- PAs have both positive and negative effects on human health and well-being

- Integrated approaches linking PA management, health and well-being are required

- In view of Aichi Target 11, we need to assess the linkages between PAs and health 


\section{Linkages between environmental degradation and human health}

Global biodiversity is decreasing at unprecedented rates, as a result of a wide range of anthropogenic activities $[1,2,3]$. Such planetary-scale transformations erode the ecosystem services on which society relies, posing numerous threats to human health [2,3]. Epidemiological studies have argued that a significant proportion of the global burden of illness is attributable to degraded ecosystems [4]. In this context, several policy instruments have been developed to bridge environmental and health policy agendas. For example, the notion that ecosystem health and human well-being are mutually reinforcing (Box 1) is increasingly being picked up by several international health strategies such as OneHealth [5] or Planetary Health [6**]. Similarly, the importance of biodiversity for human wellbeing is a core element of the United Nations Sustainable Development Goals.

Environmental change and biodiversity loss have been shown to affect existing health burdens, increasing food insecurity and annihilating rates of human development $[7,8]$. As a case in point, the decline in the availability of fish stocks is expected to spell malnutrition in many countries [9]. Furthermore, according to the "biodiversity hypothesis", reduced contact of people with natural environments leads to inadequate stimulation of immunoregulatory circuits. Declining biodiversity in an increasingly urbanized world may thus explain the global rise in the prevalence of allergies and chronic inflammatory diseases [3]. Rapid population growth, land-use change and increasing overlap between human and wildlife populations are also related to the recent spread of zoonotic and vectorborne diseases [10]. Finally, there is increasing evidence that degraded ecosystems also affect mental health [11].

Biodiversity-health linkages have often been explored by looking at ecosystem service flows (e.g., water provision) at multiple scales $\left[4,12^{* *}\right]$, but rarely taking PAs as a leading analytical unit. Consequently, the health outcomes of PAs have been largely overlooked. Calls for increasing the coverage of PAs have resulted in growing research addressing their performance in halting biodiversity loss and securing ecosystem services, with overall positive (albeit modest) outcomes 
[16]. This scholarly work is gradually broadening its analytical scope to link PAs with larger debates on human health and wellbeing [17*]. Yet, a substantial share of the research has focused on examining predominantly the negative impacts of PAs on human health. This is partly because conservation planning is inherently spatial, often segregating people from nature and undermining the well-being of Indigenous Peoples and Local Communities (IPLCs) living close to PAs [13]. Such potential negative impacts of PAs on human well-being were recognized in the Convention on Biological Diversity, asserting that PAs should not harm the well-being of IPLCs [14**]. Along these lines, the Conceptual Framework of the Intergovernmental Science-Policy Platform on Biodiversity and Ecosystem Services (IPBES) explicitly incorporates the notion of "good quality of life" in the analysis of institutional arrangements for biodiversity governance [15].

In the following section, we review the contributions of PAs to human health and well-being from a diversity of angles.

\section{Do Protected Areas support human health?}

Despite increasing awareness of the inter-linkages between nature and human health (Box 1), the overall health potential of PAs remains under-recognized. The few case-based studies assessing the impacts of PAs on human health have been addressed in different strands of literature, with distinct theoretical and methodological frames. For instance, while some of the works focus on biophysical indicators, most of them rely only on notions of subjective well-being or good quality of life [14**], with few works integrating health and well-being outcomes (Fig. 1).

A first body of literature has examined the effectiveness of PAs in delivering ecosystem services with direct health benefits that would have potentially been eroded had the PAs not been established $[18,19]$. For example, it has been shown that nearly two-thirds of the global population relies directly on PAs for freshwater provision [20]. Similarly, several studies have demonstrated the role of PAs in 
providing pollination services for food production [21] or in contributing to air purification and temperature regulation [22]. Many works have also underlined the positive role of PAs in conserving medicinal plants that sustain both local and global pharmacopeias [23], or the numerous recreational services provided by PAs, promoting healthy lifestyles [24].

In contraposition to this literature, some works have focused on examining the health impacts of PAs in the light of ecosystem disservices [25]. Under the idea that "nature sometimes kills us", this literature argues that IPLCs often carry a disproportionate burden of the health risks derived from living close to PAs [26*]. Some of these ecosystem disservices include the spread of vector-borne diseases [27], animal attacks on humans living close to PAs [28], or lower food security through the destruction of crops by wildlife [29].

Precisely, research on social aspects of conservation has also looked at the impact of some PAs upon nutrition, showing that displacements of IPLCs and restrictions to resource extraction have often resulted in increasing food insecurity and malnutrition [30,31] Although the research on PAs and nutrition is not particularly comprehensive [32], some works have shown that closing off forests to IPLCs through strict regulations generally leads to reduced food supply and nutrition deficits, e.g., anemia $\left[33^{*}, 34\right]$.

However, other studies have also shown PAs under some circumstances can contribute to alleviate malnutrition, by maintaining stocks of wild food to later be harvested beyond PA boundaries [35,13]. With most evidence confined to marine environments, this literature has shown that strict PAs may enhance local nutrition and health by rebuilding wildlife stocks, improving catch rates outside PAs and helping local people to meet their dietary requirements [36,37]. As for terrestrial ecosystems, some authors have showed that children stunting is lower close to PAs in the Congo Basin [38]. Moreover, it has also been discussed that the establishment of PAs often introduces new livelihoods that can result in positive health effects through PA-related income [13,39]. As a consequence, there is debate on whether the net impact of PAs on local people's nutrition is positive or negative [14**]. 
Part of this debate is arguably explained by the distinct health effects of PAs under different management categories [17*]. Moreover, with the establishment of new PAs promoting comanagement, agrobiodiversity or sustainable production systems in the PA periphery, the potential of PAs to improve food security should not be under-stated $[40,41]$.

Arguably the most well-researched aspect of the link between PAs and health is their effects on psychological well-being $[11,14 * *]$. Research has shown the restorative capacity of PAs and their role in fostering recovery from mental fatigue, reducing stress levels, assisting cognitive functioning, and improving the overall psychological state [32,42]. Interestingly, these psychological benefits have been shown to be higher in areas of greater biodiversity [43,44]. Recent research on naturebased tourism has documented that visiting PAs often results in increased wellbeing [45]. Indeed, there is increasing understanding of the positive health outcomes of PAs, with the Australian program "Healthy Parks, Healthy People" being one of the most paradigmatic examples of this trend [11].

Nevertheless, evidence on the impacts of PAs on the well-being of IPLCs is still contentious. While there are works showing how conservation has improved the health status of many IPLCs near PAs $\left[14^{* *}, 39\right]$, the opposite also holds true. Due to the colonial legacy of conservation (e.g., displacement and exclusion), there are numerous cases in which the establishment of strict PAs has contributed to higher levels of psychological distress and mental illness amongst IPLCs [46,47]. While many IPLCs indeed find spiritual connections with nature as a source of wellbeing [48], the psychological implications of exclusionary PAs are significant.

Finally, an emerging body of literature is trying to assess the role of PAs in relation to Emerging Infectious Diseases (EIDs). PAs shape many socio-ecological factors related to disease prevalence, including land-use, biodiversity, and socioeconomic conditions [49,50]. Hence, PAs may drive disease prevalence by influencing vector and host presence and by controlling human exposure to vector species (Box 2). For instance, it is known that deforestation and hunting in non-protected areas 
disrupt ecological communities with positive knock-on effects on mosquito populations (e.g., through predation release, improved breeding habitat or increased abundance in dead-end hosts; [10]).

However, there is debate on the pathways through which PAs shape the distribution of infectious diseases (e.g., malaria). While some authors have discussed that PAs could reduce malaria risk by decreasing human exposure to anopheline breeding habitats [51], others have argued that PAs actually favor higher exposure to malaria [52]. At the same time, other works have emphasized that PAs could reduce malaria prevalence through improved socio-economic conditions [53]. Such contradictory findings are partly explained by different methods and datasets at various spatio-temporal scales, with certain confounding factors largely unaddressed. As a result, evidence on the role of PAs in shaping EIDs dynamics remains inconclusive. Moreover, and although positive cases of co-benefits between biodiversity conservation and disease control exist, it is noteworthy that the complex effects of PAs on EIDs vary with disease ecology, PA management categories and landscape attributes at various spatio-temporal scales $[51,54]$.

\section{Need for systematic integrative approaches}

With progress to achieve Aichi Target 11 of protecting at least $17 \%$ of terrestrial and $10 \%$ of marine areas globally by 2020 , assessing the role of PAs in supporting human health remains paramount. Yet, such role cannot be directly extrapolated from studies on the health benefits of nature, given that PAs, as organizational units embedded within certain socio-political contexts, inevitably alter humannature interactions [55]. Responding to recent calls to improve our knowledge of the role between PAs and human health and well-being [14**], we integrate developments from different research fronts with the aim of bringing forward the discussion and stimulate new analytical approaches.

Assessments of the social impacts of PAs should acknowledge different dimensions of human health and well-being (Box 1). The evidence to date on positive and negative aspects of PAs derives from 
an heterogeneous sample of studies addressing very specific aspects of health, which have been often conducted opportunistically and mostly lacking robust study designs and/or baseline measures $\left[14^{* *}\right]$, thus not allowing to guide policy actions. Yet baseline data exists for a number of health indicators globally, and different long-term health monitoring schemes are being promoted in the vicinity of many PAs. Examples include USAID's Health Survey Data, the World Bank's Living Standards or the database of the Poverty Environment Network [14**,56], all of which could potentially be analyzed from a PA perspective. Similarly, in countries such as Canada or Australia large amounts of indigenous health data exist [57], some of which have been collected near PAs. There are also numerous PAs with health monitoring programs in neighboring local communities. Such datasets could serve a purpose in furthering our understanding of the linkages between PAs and health. Yet, the establishment of monitoring networks that include simultaneous measures of both aspects of PA effectiveness (ecosystem and human health) should be a priority.

PA impacts on health may be direct or indirect, in situ or ex situ (Figure 2, Panel A). Given that the core areas of PAs are generally uninhabited, most health impacts are expected at the PA periphery. Yet, some of them take place at larger scales. For instance, the rising numbers of tourists visiting PAs challenge the assessment of health impacts only at the local level, but also raise important questions on "whose health" is being evaluated. Research on the links between PAs and health should ideally account for both local and non-local impacts, avoiding biased samples (only surveying tourists) that serve certain political or economic agendas. Moreover, it is also important to evaluate the role of PAs in supporting future health. For instance, many PAs conserve plants underpinning the future provisioning of medicines for both local and prospective global uses [58]. Assessments of the linkages between PAs and health should thus find a balance between the health prospects of both present and future generations.

Along these lines, it is crucial to recognize that health is also dependent on the socio-economic context. Socio-economic factors are known to affect the conservation effectiveness of PAs [59]; yet, 
they are rarely considered when evaluating PA impacts on health or well-being. Aspects such as PA permeability have been also argued to impact health [54]. For example, strict PAs (IUCN Category I) will have different impacts than PAs with sustainable use of natural resources (Category VI). PA size and isolation will also play an important role. Panel B in Figure 2 illustrates a few alternative settings of PAs varying in governance type, size and isolation, particularly due to land-use changes at the PA periphery. Here we deliberate on the potential health consequences of such scenarios, while stressing that empirical evidence is largely lacking and that analytical approaches accounting for PA attributes are urgently needed.

PAs of Type A (i.e., small size, strict protection and highly degraded periphery) have often induced exclusion of IPLCs (through restrictions on resource use), undermining food security and well-being [35,60**]. Malnutrition increases immunity deficiency and susceptibility to infection. IPLCs living in degraded PA peripheries are thus potentially more vulnerable to zoonotic and vector-borne diseases, following changes in the distribution of vector species. Potential benefits associated to Type A would be contingent on infrastructure development and poverty alleviation initiatives, which should be rarer for small areas of strict protection compared to Types B and C. Such developments could bring about improvements in healthcare delivery; yet, these are unlikely to counterbalance most health costs.

Types B and C may instead lead to more co-benefits for both health and biodiversity. Increased PA size associated to sustainable resource extraction either within Type B or within the buffer zone of Type $\mathrm{C}$ would decrease health costs associated to alienation and malnutrition, while incomes from tourism could bring livelihood diversification and poverty alleviation in the periphery (Type B, Fig. 1). From the perspective of EIDs, the evidence is still inconclusive, and outcomes may well be disease-dependent as well as context-specific (Box 2). Yet, we expect that large core areas of strict protection surrounded by sustainable-use peripheries (Type C), would decrease the probability of EIDs expansion, while best conserving species and habitats. In this case, a well-managed buffer zone 
would hold a significant portion of semi-natural habitats allowing for sustainable use by IPLCs, with benefits in terms of livelihoods, nutrition and well-being.

\section{Future research directions}

While research on the linkages between human and ecosystem health grows, this review stresses an urgent need to address specifically the role of PAs in supporting human health. In this review, we have identified important research gaps that preclude us from developing a clear picture of the overall health effects of PAs. These include among others: i) integration and comparison of the heterogeneous set of health dimensions, ii) a comprehensive overview of different human population targets for health assessments (i.e. whose health is being evaluated; within and beyond PAs), and iii) a contextdependent analytical framework incorporating spatial, environmental and socio-economic factors (including PA management types). Additionally, while studies on the effectiveness of PAs in safeguarding biodiversity are becoming ever more common, we are not aware of any single study linking effectiveness of biodiversity conservation with health outcomes. Research at all these fronts will shed light into many ongoing debates, and be able to clarify why some PAs may promote health while others not.

In order to tackle the abovementioned gaps, we highlight that tools and datasets are already available to support substantial advances, while others need yet to be implemented. For instance, many of the health monitoring databases mentioned above could be used to develop a more integrated overview of the health impacts of PAs. Similarly, diverse large-scale environmental, geographical and sociopolitical datasets can already be linked to disentangle the effects of particular health indicators in different contexts. Research systematically comparing the health outcomes of PAs under different management categories is particularly called upon and a straightforward step given the available data. 
At finer scales, emphasis should be placed on buffer zones around PAs in order to disentangle the complex linkages between land-use change, natural resource use and socio-economic conditions and understand how they influence different aspects of health, for instance linking nutrition and emerging infectious disease impacts. Replicated and standardized studies of this type in multiple contexts are very much in order.

All things considered, however, we view as paramount the need to strategically develop and implement, integrated, large scale co-monitoring schemes in order to assess synergies and trade-offs between biodiversity conservation and human health. Monitoring biodiversity responses to human disturbance inside PAs, as well as in the PA periphery and buffer zones, and understanding how this in turn affects different dimensions of human health across different types of PAs is an urgent priority.

We end with a note of warning regarding reports of negative impacts of PAs on human health. While empirical research on the reality of health risks is desirable, caution is needed when communicating research outcomes to wider audiences in order to avoid misinformed and unsupported health concerns undermining long-term conservation efforts [61].

\section{Acknowledgements}

This research was funded by the Academy of Finland (grant agreement nr. 292765). JT was supported by the Nessling Foundation. ÁF-LL was also supported by the Kone Foundation. We also thank J. Helle for cartographic assistance, and A. Villers for insightful comments and ideas. 
References and recommended reading

Papers of particular interest, published within the period of review, have been highlighted as:

*of special interest

**of outstanding interest

1. Barnosky AD, Matzke N, Tomiya S, Wogan GOU, Swartz B, Quental TB, Marshall C, McGuire JL, Lindsey EL, Maguire KC, et al.: Has the Earth's sixth mass extinction already arrived? Nature 2011, 471:51-57.

2. Cardinale BJ, Duffy JE, Gonzalez A, Hooper DU, Perrings C, Venail P, Narwani A, Mace GM, Tilman D, Wardle DA, et al.: Biodiversity loss and its impact on humanity. Nature 2012, 489:326-326.

3. Hanski I, von Hertzen L, Fyhrquist N, Koskinen K, Torppa K, Laatikainen T, Karisola P, Auvinen P, Paulin L, Makela MJ, et al.: Environmental biodiversity, human microbiota, and allergy are interrelated. Proc Natl Acad Sci U S A 2012, 109:8334-8339.

4. Raudsepp-Hearne C, Peterson GD, Bennett EM: Ecosystem service bundles for analyzing tradeoffs in diverse landscapes. Proc Natl Acad Sci U S A 2010, 107:5242-5247.

5. Buttke DE, Decker DJ, Wild MA: The role of One Health in wildlife conservation: a challenge and opportunity. $J$ Wildl Dis 2015, 51:1-8.

6**. Whitmee S, Haines A, Beyrer C, Boltz F, Capon AG, De Souza Dias BF, Ezeh A, Frumkin H, Gong P, Head P, et al.: Safeguarding human health in the Anthropocene epoch: Report of the Rockefeller Foundation-Lancet Commission on planetary health. Lancet 2015, 386:1973-2028.

Key reading on the linkages between environmental degradation and human health.

7. Redford KH, Myers SS, Ricketts TH, Osofsky SA: Human health as a judicious conservation opportunity. Conserv Biol 2014, 28:627-629.

8. $\quad$ Morris AL, Guégan J-F, Andreou D, Marsollier L, Carolan K, Le Croller M, Sanhueza D, Gozlan RE: Deforestation-driven food-web collapse linked to emerging tropical infectious disease, Mycobacterium ulcerans. Sci Adv 2016, 2:e1600387.

9. Golden CD, Allison EH, Dey MM, Halpern BS, McCauley DJ, Smith M, Vaitla B, Zeller D, Myers SS, Cheung WWL, et al.: Fall in fish catch threatens human health. Nature 2016, 534:317-320.

10. Laporta GZ, Prado PIK, Kraenkel RA, Coutinho RM, Sallum MAM: Biodiversity Can Help Prevent Malaria Outbreaks in Tropical Forests. PLoS Negl Trop Dis 2013, 7:e2139 
11. Maller C, Townsend M, Leger LS, Henderson-Wilson C, Pryor A, Prosser L, Moore M: Healthy parks, healthy people: The health benefits of contact with nature in a park context. Melbourne, Australia: Deakin University and Parks Victoria; 2008.

12**. Bennett EM, Cramer W, Begossi A, Cundill G, Díaz S, Egoh BN, Geijzendorffer IR, Krug CB, Lavorel S, Lazos E, et al.: Linking biodiversity, ecosystem services, and human wellbeing: three challenges for designing research for sustainability. Curr Opin Environ Sustain 2015, 14:76-85.

The authors address the need to link ecosystem services, human well-being and biodiversity in order to improve sustainable ecosystem management.

13. Turner WR, Brandon K, Brooks TM, Gascon C, Gibbs HK, Lawrence KS, Mittermeier RA, Selig ER: Global Biodiversity Conservation and the Alleviation of Poverty. Bioscience 2012, 62:85-92.

14**. McKinnon MC, Cheng SH, Dupre S, Edmond J, Garside R, Glew L, Holland MB, Levine E, Masuda YJ, Miller DC, et al.: What are the effects of nature conservation on human well-being? A systematic map of empirical evidence from developing countries. Environ Evid 2016, 5:8.

Key meta-analysis investigating the linkages between conservation and human well-being. The paper shows that most articles on this topic do not evaluate human health outcomes, and that biases in the extent and robustness of articles are still common.

15. Díaz S, Demissew S, Carabias J, Joly C, Lonsdale M, Ash N, Larigauderie A, Adhikari JR, Arico S, Báldi A, et al.: The IPBES Conceptual Framework - connecting nature and people. Curr Opin Environ Sustain 2015, 14:1-16.

16. Geldmann J, Barnes M, Coad L, Craigie ID, Hockings M, Burgess ND: Effectiveness of terrestrial protected areas in reducing habitat loss and population declines. Biol Conserv 2013, 161:230-238.

17*. Ban NC, Davies TE, Aguilera SE, Brooks C, Cox M, Epstein G, Evans LS, Maxwell SM, Nenadovic M: Social and ecological effectiveness of large marine protected areas. Glob Environ Chang 2017, 43:82-91.

This global meta-analysis investigates social, ecological and governance characteristics of successful large marine PAs. This study constitutes an important first step in identifying factors affecting social well-being in marine PAs.

18. Naeem S, Chazdon R, Duffy JE, Prager C, Worm B: Biodiversity and human wellbeing: an essential link for sustainable development. Proc R Soc B Biol Sci 2016, 283:20162091.

19. Xu W, Xiao Y, Zhang J, Yang W, Zhang L, Hull V, Wang Z, Zheng H, Liu J, Polasky $\mathrm{S}$, et al.: Strengthening protected areas for biodiversity and ecosystem services in China. Proc Natl Acad Sci U S A 2017, 114:1601-1606.

20. Harrison IJ, Green PA, Farrell TA, Juffe-Bignoli D, Sáenz L, Vörösmarty CJ:

Protected areas and freshwater provisioning: a global assessment of freshwater provision, threats and management strategies to support human water security. Aquat Conserv Mar Freshw Ecosyst 2016, 26:103-120. 
IPBES: The assessment report of the Intergovernmental Science-Policy Platform on Biodiversity and Ecosystem Services on pollinators, pollination and food production. Bonn, Germany: Secretariat of the Intergovernmental Science-Policy Platform on Biodiversity and Ecosystem Services; 2016.

22. Baró F, Chaparro L, Gómez-Baggethun E, Langemeyer J, Nowak DJ, Terradas J:

Contribution of ecosystem services to air quality and climate change mitigation policies: the case of urban forests in Barcelona, Spain. Ambio 2014, 43:466-479.

23. Amjad MS, Qaeem M faisal, Ahmad I, Khan SU, Chaudhari SK, Zahid Malik N, Shaheen H, Khan AM: Descriptive study of plant resources in the context of the ethnomedicinal relevance of indigenous flora: A case study from Toli Peer National Park, Azad Jammu and Kashmir, Pakistan. PLoS ONE 2017, 12:e0171896.

24. Wolf ID, Wohlfart T: Walking, hiking and running in parks: A multidisciplinary assessment of health and well-being benefits. Landsc Urban Plan 2014, 130:89-103.

25. Von Döhren P, Haase D: Ecosystem disservices research: A review of the state of the art with a focus on cities. Ecol Indic 2015, 52:490-497.

26*. Shackleton CM, Ruwanza S, Sinasson Sanni GK, Bennett S, De Lacy P, Modipa R, Mtati N, Sachikonye M, Thondhlana G: Unpacking Pandora's Box: Understanding and Categorising Ecosystem Disservices for Environmental Management and Human Wellbeing. Ecosystems 2016, 19:587-600.

The authors review the concept of ecosystem disservices and their implications in terms of human wellbeing.

27. Malan HL, Appleton CC, Day JA, Dini J: Wetlands and invertebrate disease hosts: Are we asking for trouble? Water SA 2009, 35:753-768.

28. Barua M, Bhagwat SA, Jadhav S: The hidden dimensions of human-wildlife conflict: Health impacts, opportunity and transaction costs. Biol Conserv 2013, 157:309-316.

29. Nyamwamu RO: Implications of Human-Wildlife Conflict on Food Security among Smallholder Agro-Pastoralists: A Case of Smallholder Maize (Zea mays) Farmers in Laikipia County, Kenya. World J Agric Res 2016, 4:43-48.

30. Foale S, Adhuri D, Aliño P, Allison EH, Andrew N, Cohen P, Evans L, Fabinyi M, Fidelman P, Gregory C, et al.: Food security and the Coral Triangle Initiative. Mar Policy 2013, 38:174-183.

31. Nakamura EM, Hanazaki N: Protected Area Establishment and Its Implications for Local Food Security. Hum Ecol Rev 2016, 22:1-22.

32. Stolton S, Dudley N: Vital Sites. The contribution of protected areas to human health. Gland, Switzerland: World Wide Fund for Nature and Equilibrium Research; 2010.

33*. Golden CD, Fernald LCH, Brashares JS, Rasolofoniaina BJR, Kremen C: Benefits of wildlife consumption to child nutrition in a biodiversity hotspot. Proc Natl Acad Sci U S A 2011, 108:19653-19656.

\footnotetext{
The authors show that declining fish stocks will undermine food security in many developing countries.
} 
34. Sylvester O, Segura AG, Davidson-Hunt IJ: The protection of forest biodiversity can conflict with food access for Indigenous people. Conserv Soc 2016, 14:279-290.

35. Dudley N, Mansourian S, Suksuwan S: Arguments for Protection: Protected areas and poverty reduction. Gland, Switzerland: World Wide Fund for Nature and Equilibrium Research; 2008.

36. McNally CG, Uchida E, Gold AJ: The effect of a protected area on the tradeoffs between short-run and long-run benefits from mangrove ecosystems. Proc Natl Acad Sci U S A 2011, 108:13945-13950.

37. Alva S, Johnson K, Jacob A, D’Agnes H, Mantovani R, Evans T: Marine protected areas and children's dietary diversity in the Philippines. Popul Environ 2016, 37:341-361.

38. Fa JE, Olivero J, Real R, Farfán MA, Márquez AL, Vargas JM, Ziegler S, Wegmann M, Brown D, Margetts B, et al.: Disentangling the relative effects of bushmeat availability on human nutrition in central Africa. Sci Rep 2015, 5:8168.

39. Baird TD: Conservation and unscripted development: proximity to park associated with development and financial diversity. Ecol Soc 2014, 19:4.

40. Harvey CA, Komar O, Chazdon R, Ferguson BG, Finegan B, Griffith DM, MartínezRamos M, Morales H, Nigh R, Soto-Pinto L, et al.: Integrating agricultural landscapes with biodiversity conservation in the Mesoamerican hotspot. Conserv Biol 2008, 22:8-15.

41. Webster FJ, Cohen PJ, Malimali S, Tautai M, Vidler K, Mailau S, Vaipuna L, Fatongiatau V: Detecting fisheries trends in a co-managed area in the Kingdom of Tonga. Fish Res 2017, 186:168-176.

42. Wolf ID, Stricker HK, Hagenloh G: Outcome-focused national park experience management: transforming participants, promoting social well-being, and fostering place attachment. J Sustain Tour 2015, 23:358-381.

43. Fuller RA, Irvine KN, Devine-Wright P, Warren PH, Gaston KJ: Psychological benefits of greenspace increase with biodiversity. Biol Lett 2007, 3:390-4.

44. Wolf LJ, zu Ermgassen S, Balmford A, White M, Weinstein N: Is Variety the Spice of Life? An Experimental Investigation into the Effects of Species Richness on Self-Reported Mental Well-Being. PLOS ONE 2017, 12:e0170225.

45. Puhakka R, Pitkänen K, Siikamäki P: The health and well-being impacts of protected areas in Finland. J Sustain Tour 2017, doi:10.1080/09669582.2016.1243696.

46. Dowie, M: Conservation Refugees. The Hundred-Year Conflict between Global Conservation and Native Peoples. London, United Kingdom: Massachusetts Institute of Technology; 2009.

47. Snodgrass JG, Upadhyay C, Debnath D, Lacy MG: The mental health costs of human displacement: A natural experiment involving indigenous Indian conservation refugees. World Dev Perspect 2016, 2:25-33.

48. Sangha KK, Le Brocque A, Costanza R, Cadet-James Y: Ecosystems and indigenous well-being: An integrated framework. Glob Ecol Conserv 2015, 4:197-206. 
49. Cumming GS, Abolnik C, Caron A, Gaidet N, Grewar J, Hellard E, Henry DAW, Reynolds C: A social-ecological approach to landscape epidemiology: geographic variation and avian influenza. Landsc Ecol 2015, 30:963-985.

50. de Vos A, Cumming GS, Cumming DHM, Ament JM, Baum J, Clements HS, Grewar JD, Maciejewski K, Moore C: Pathogens, disease, and the social-ecological resilience of protected areas. Ecol Soc 2016, 21:20.

51. Bauch SC, Birkenbach AM, Pattanayak SK, Sills EO: Public health impacts of ecosystem change in the Brazilian Amazon. Proc Natl Acad Sci U S A 2015, 112:7414-7419.

52. Valle D, Clark J: Conservation Efforts May Increase Malaria Burden in the Brazilian Amazon. PLoS ONE 2013, 8:e57519.

53. Taber ED, Smithwick EAH: Influence of protected areas on malaria prevalence in Sub-Saharan Africa. Appl Geogr 2015, 64:35-45.

54. Hahn MB, Olson SH, Vittor AY, Barcellos C, Patz JA, Pan W: Conservation efforts and malaria in the Brazilian Amazon. Am J Trop Med Hyg 2014, 90:591-594.

55. Milner-Gulland EJ: Interactions between human behaviour and ecological systems. Philos Trans R Soc B Biol Sci 2012, 367:270-278.

56. Reyes-García V, Babigumira R, Pyhälä A, Wunder S, Zorondo-Rodríguez F, Angelsen A: Subjective Wellbeing and Income: Empirical Patterns in the Rural Developing World. J Happiness Stud 2016, 17:773-791.

57. Stephens C, Porter J, Nettleton C, Willis R: Disappearing, displaced, and undervalued: a call to action for Indigenous health worldwide. Lancet 2006, 367:2019-2028.

58. Chen SL, Yu H, Luo HM, Wu Q, Li CF, Steinmetz A: Conservation and sustainable use of medicinal plants: problems, progress, and prospects. Chin Med 2016, 11:37.

59. $\quad$ Eklund J, Cabeza M: Quality of governance and the effectiveness of protected areas: crucial concepts for conservation planning. Ann N Y Acad Sci 2017, doi:10.1111/nyas.13284.

60**. Oldekop JA, Holmes G, Harris WE, Evans KL: A global assessment of the social and conservation outcomes of protected areas. Conserv Biol 2016, 30:133-141.

This global meta-analysis explores how PAs affect the well-being of local peoples, revealing that PAs associated with positive socieconomic outcomes often report positive conservation outcomes.

61. Hanisch-Kirkbride SL, Riley SJ, Gore ML: Wildlife Disease and Risk Perception. $J$ Wildl Dis 2013, 49:841-849.

62. Biedenweg K, Stiles K, Wellman K: A holistic framework for identifying human wellbeing indicators for marine policy. Mar Policy 2016, 64:31-37.

63. Loring PA, Hinzman MS, Neufeld H: Can people be sentinels of sustainability? Identifying the linkages among ecosystem health and human well-being. Facets 2016, 1:148162. 
64. Aronson JC, Blatt CM, Aronson TB: Restoring ecosystem health to improve human health and well-being: physicians and restoration ecologists unite in a common cause. Ecol Soc 2016, 21:39.

65. Donatuto J, Grossman EE, Konovsky J, Grossman S, Campbell LW: Indigenous Community Health and Climate Change: Integrating Biophysical and Social Science Indicators. Coast Manag 2014, 42:355-373.

66. Jones KKE, Patel NGN, Levy MA, Storeygard A, Balk D, Gittleman JL, Daszak P: Global trends in emerging infectious diseases. Nature 2008, 451:990-993.

67. Karesh WB, Dobson A, Lloyd-Smith JO, Lubroth J, Dixon MA: Ecology of zoonoses: natural and unnatural histories. Lancet 2012, 380:1936-1945.

68. Basler CF: West African Ebola Virus Strains: Unstable and Ready to Invade? Cell Host Microbe 2017, 21:316-318.

69. Judson SD, Fischer R, Judson A, Munster VJ: Ecological Contexts of Index Cases and Spillover Events of Different Ebolaviruses. PLoS Pathog 2016, 12:e1005780.

70. Rouquet P, Froment JM, Bermejo M, Kilbourn A, Karesh W, Reed P, Kumulungui B, Yaba P, Délicat A, Rollin PE, et al.: Wild animal mortality monitoring and human ebola outbreaks, Gabon and Republic of Congo, 2001-2003. Emerg Infect Dis 2005, 11:283-290.

71. Leendertz SAJ: Testing new hypotheses regarding ebolavirus reservoirs. Viruses 2016, 8:30.

72. Singh RK, Dhama K, Malik YS, Ramakrishnan MA, Karthik K, Khandia R, Tiwari R, Munjal A, Saminathan M, Sachan S, et al.: Ebola virus - epidemiology, diagnosis and control: threat to humans, lessons learnt and preparedness plans - an update on its 40 year's journey. Vet $Q$ 2017, doi:10.1080/01652176.2017.1309474.

73. Koerner SE, Poulsen JR, Blanchard EJ, Okouyi J, Clark CJ: Vertebrate community composition and diversity declines along a defaunation gradient radiating from rural villages in Gabon. J Appl Ecol 2017, doi:10.1111/1365-2664.12798.

74*. Rulli MC, Santini M, Hayman DTS, D’Odorico P: The nexus between forest fragmentation in Africa and Ebola virus disease outbreaks. Sci Rep 2017, 7:41613.

The authors illustrate that in recent outbreaks of Ebola virus disease, most index cases in humans (or spillover from wildlife reservoirs) occurred in hotspots of forest fragmentation.

75. Leendertz SAJ, Wich S, Ankrenaz M, Bergl R, Gonder M, Humle T, Leendertz FH: Ebola in great apes - current knowledge, possibilities for vaccination and the implications for conservation and human health. Mamm Rev 2017, doi:10.1111/mam.12082. 


\section{Box 1. Human Health, Well-Being and Ecosystem Health}

Numerous frameworks exist for conceptualizing health and well-being, ranging in focus from the individual to the nation, and hailing from such diverse disciplines as anthropology, economics or epidemiology $[62,63]$. Such frameworks have used a wide array of indicators to measure the health, ranging from mortality (e.g., child mortality), morbidity (e.g., prevalence, incidence), health status (e.g., high blood pressure), nutritional (e.g., children stuntness), social health (e.g., substance abuse), or health-system (e.g., healthcare delivery) indicators.

Although a full review of these frameworks is beyond the scope of this paper, it is important to note that despite their theoretical differences, most of these works share a general vision of linking human and ecosystem health $[18,64]$. Frameworks in this vein resonate with indigenous peoples' philosophical concepts of living in harmony with nature (e.g., Andean notion of Mother Earth), identifying kinship between people and nature as a determinant of human well-being [15]. Overall, these ever-more holistic definitions of human health (reflecting the origin of the word, derived from the Greek ' $h a l$ ' or 'whole') are providing new opportunities for conservation managers to play a greater role in supporting human health than in the past [32]. As a result, there have been recurrent calls for a shift from purely biophysical measures of health to broader well-being indicators, targeting life satisfaction, good quality of life, or happiness, to cite just a few $[62,65]$. Many of these indicators have also started to gain prominence in environmental discourses (e.g., Sumak Kawsay in Ecuador; Gross National Happiness in Bhutan). 


\section{Box 2. Protected Areas or their periphery as hotspots of infectious disease emergence?}

Up to two-thirds of known human infectious pathogens have emerged from animals [66]. This transmission from other species to humans fits with pathogen ecology and evolution, but the opportunities for animal-tohuman pathogen spillover are higher with increasing human encroachment in natural habitats, particularly in the tropics [67]. Major disease hotspots appear to be at the interface between natural and degraded ecosystems, such as at the periphery of PAs. However, few studies have taken PAs as a leading analytical unit in epidemiological studies [53].

A topical case is that of Ebolaviruses, extremely contagious pathogens causing lethal hemorrhagic fever disease in humans and animals with high fatality rates. They have been repeatedly reemerging across the African equatorial belt since 1976 [68]. Despite the multiple Ebola outbreaks, we still have limited understanding of the reservoir host species and the environmental contexts favoring animal-to-human transmissions [69]. For instance, RNA of the Zaire Ebola virus (EBOV) has been detected in multiple wildlife species such as three species of bats, duikers (Cephalophus species), gorillas (Gorilla gorilla), chimpanzees (Pan troglodytes) and various rodents, remaining debatable which are the natural reservoirs [70,71].

Ebola outbreaks have indeed been linked to contacts with wildlife. The cases in Gabon and DRC, in proximity to Odzala Kokoua National Park in 2001-2003 (Fig. 2), started when locals found and manipulated carcasses of infected mammals at the PA periphery [72]. Hunting pressure is high in North-eastern Gabon and affects large-scale animal communities [73], highlighting the role of bushmeat familial consumption as a high-risk behavior in these local communities. Yet outbreaks have also been linked to environmental change in Central and West Africa, with index cases in humans occurring in hotspots of forest fragmentation [74*]. The maps below (Fig. 2) illustrate how Ebola emergence locations (marked A, B and C) correspond to areas of recent deforestation, in the periphery of the Odzala Kokoua National Park. This suggests an interaction between landuse change and bushmeat hunting enhancing zoonotic disease outbreaks. While the role of PAs in the spatial dynamics of EVD outbreaks has not been investigated, caution is needed when interpreting spatial patterns. Although PAs are sometimes portrayed as EIDs hotspots because of the species they protect within [52], EIDs emergence might instead be attributable to the processes of fast land degradation happening beyond their borders.

Given that EIDs are responsible for over one billion human cases per year, we urge research to investigate i) how the interaction of deforestation and bushmeat consumption affect wildlife communities and particularly the host species around PAs; ii) how this resonates into spatial dynamics of EID emergence taking into account variation in livelihoods, human malnutrition and variation in PA governance and law enforcement; iii) the feasibility of an international protected area network of wildlife and human health monitoring combined with public education about zoonotic diseases particularly at PA periphery [75]. 
A) Scale of impacts on health related Ecosystem Services

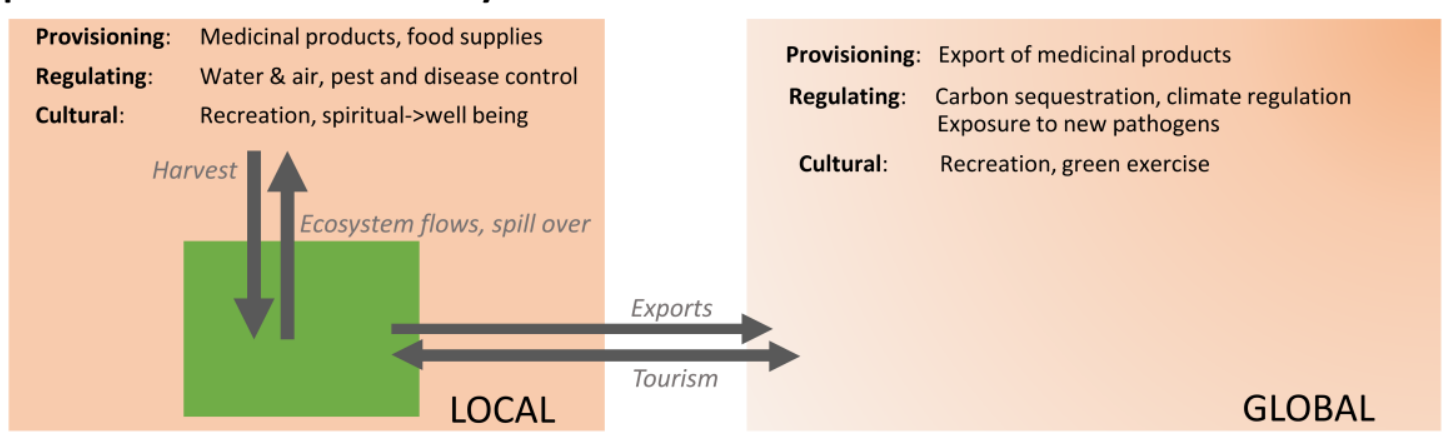

B) Context dependence: PA governance and design (size and isolation)

Protected Area, strict

Protected Area, extractive use, entrance allowed

Buffer zone, largely degraded

Buffer zone, seminatura
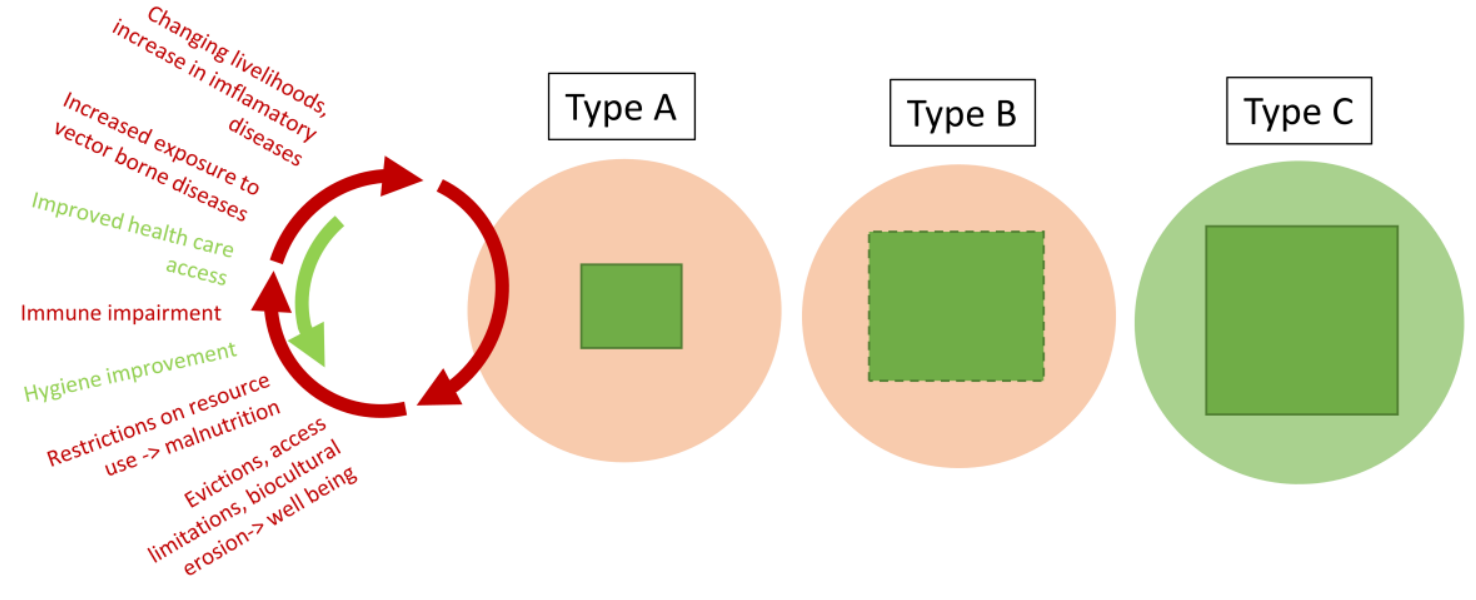

532 Figure 1. Linkages between human health, ecosystem services and PA management. Panel

533 A. Scale of impacts on health through different ecosystem services. Impacts can be local or global, within or outside the PA. Processes marked in cursive. Panel B illustrates different PA settings.

535 Protected areas can have different restrictive uses, from complete exclusion of human actions to 536 sustainable extractive uses of different types. In addition, they vary in their spatial design, with 537 aspects of shape, size and isolation affecting both biodiversity as well as health impacts. 

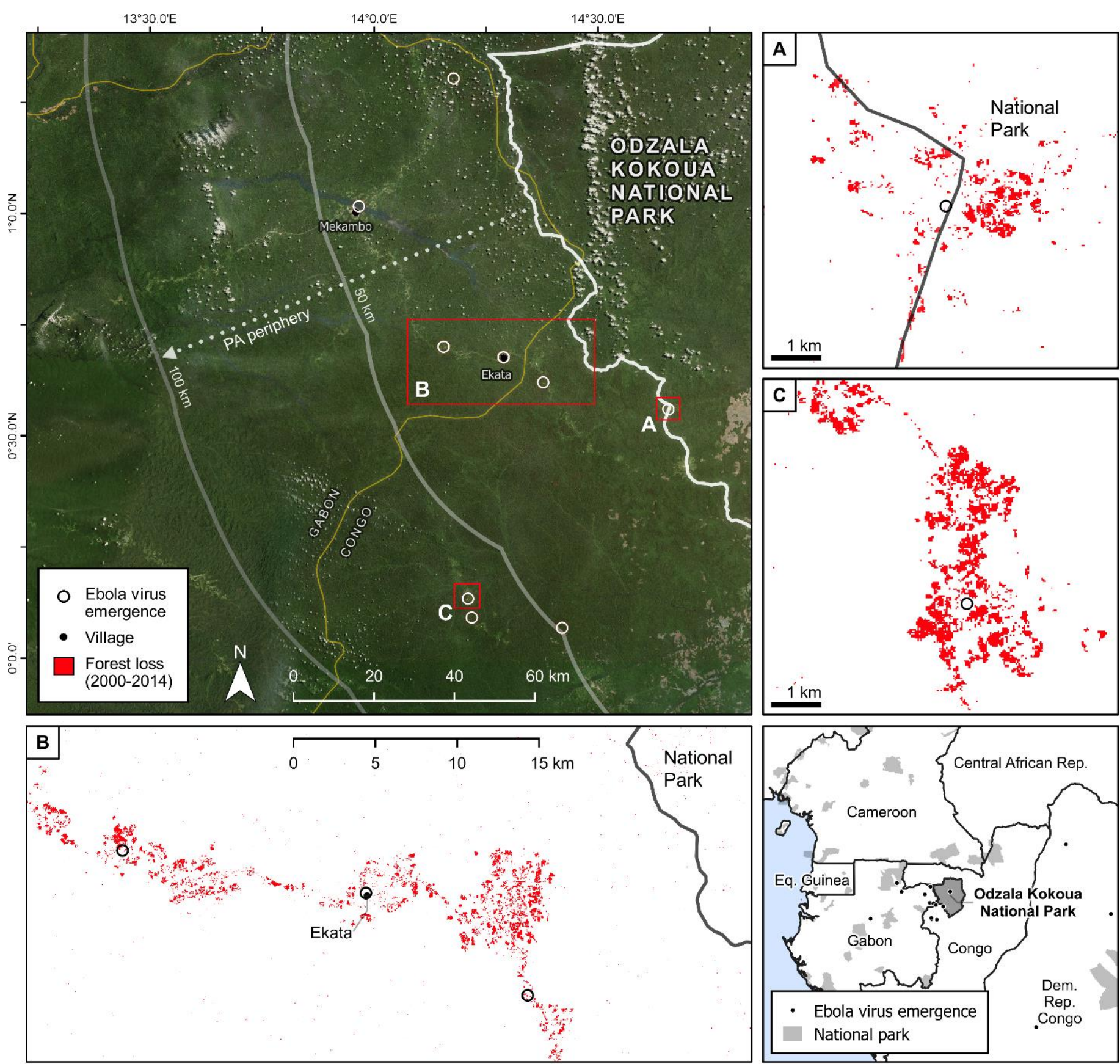

Figure 2. Ebola virus emergence in the periphery of Odzala Kokoua National Park in relation 